\title{
Considering transparency and value for fairer drug prices
}

- Cite as: CMAJ 2018 January 8;190:E30-1. doi: 10.1503/cmaj.109-5538

Posted on cmajnews.com on Dec. 6, 2017.

ix months after the federal government began overhauling how it regulates drug prices, it has tabled a five-point plan for new regulations. Much of the plan consists of longfamiliar measures, such as comparing list prices to those in other countries. But two of the proposed regulations- compelling drug-makers to disclose the true prices paid for drugs, and assessing prices based on actual value to patients - have the potential to radically reduce drug prices, according to Steven Morgan, a health economist at the University of British Columbia. "It will depend," he warns, though, "on how the regulations are implemented."

The federal government is under pressure to do something bold. Spending by the federal and provincial governments on patented drugs costing more than $\$ 10000$ per patient annually increased $60 \%$ last year, and spending on brand-name pharmaceuticals as a whole rose $18 \%$.

Canada's current drug-price regulation framework "does not consider whether the price of a drug reflects its value to patients," Health Canada explained when it launched consultations on the issue. But the government plans to start considering value using a strategy that "identifies, measures, and compares the costs and benefits of a given medicine to patients and the health care system."

The provinces already do a pharmacoeconomic evaluation of drugs to consider how well they work and how much they should cost. But having federal regulators do it when they assess drugs for marketing approval "represents a huge opportunity," said Helen Stevenson, president of Reformulary Group, which advises private drug plans on spending controls.
One of the most vocal proponents of this concept - known as "value-based pricing" - is Dr. Peter Bach, director of the Center for Health Policy and Outcomes at the Memorial Sloan Kettering Cancer Center in New York City. Speaking recently at TEDMED, Bach emphasized
Once a price has been calculated using this approach, Bach added, it should be compared with the actual prices paid by insurers and bulk purchasers. At present, the real prices paid for drugs are generally kept secret in Canada and the United States. Adopting value-based pricing, how-

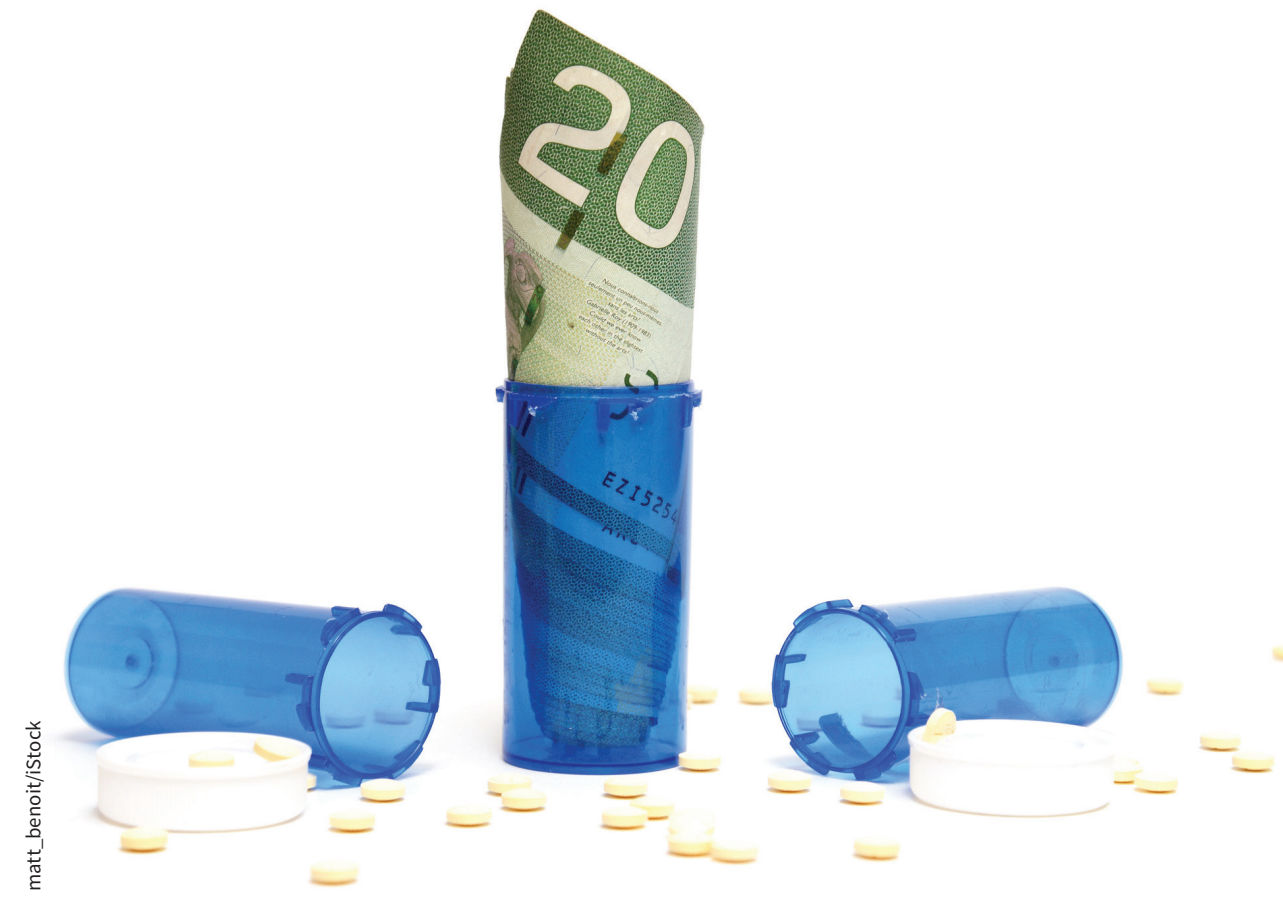

The actual prices that public and private insurers pay for drugs is often kept secret.

the potential for value-based pricing to curb profiteering by drug-makers.

A drug's true value, according to Bach, should be calculated using the efficacy and safety data supplied by drug companies to government safety regulators. This would enable price-setting based on a drug's health benefits, adverse effects, scientific novelty, research costs, and the relative seriousness of the disease it's designed to treat. ever, will require dramatic reforms aimed at making price-setting "transparent, fair and sustainable," said Bach.

The Patented Medicines Price Review Board (PMPRB), Canada's drug-price watchdog, aims to adopt something akin to this approach. The government plans to use data contained in regulatory filings by pharmaceutical companies to help determine fair prices, according to Tanya Potashnik, 
director of policy and economic analysis for the board. "That should be part of the consideration," said Potashnik.

When Health Canada initially revealed its interest in value-based pricing (also called "pharmacoeconomic analyses"), Innovative Medicines Canada, the industry group that represents patented drug companies, voiced concern about the approach.

"The ability to negotiate confidential reduced prices has benefited Canadians," the group suggested, adding that "pharmacoeconomic analyses are not mechanisms that should be used to regulate excessive drug prices."

If the government proceeds with the proposals, new regulatory powers should be applied only to new products, to "avoid significant uncertainty with respect to the compliance status of currently regulated products," stated the industry association.

But according to Morgan, implementing value-based pricing isn't enough. In addition to challenging unfair prices, the government should challenge drug companies' ability to claim monopoly privileges before prices are set, especially if any of the research in the development process was publicly funded.

"Why should we automatically transfer all of the value of a drug to the firm that holds the patent and markets it?" Morgan asked.

Paul Webster, Toronto, Ont. 